\title{
WHICH HEALTH PROFESSIONALS ARE MOST AT RISK FOR CARDIOVASCULAR DISEASE? OR DO NOT BE A MANAGER
}

\author{
ELISKA SOVOVA ${ }^{1}$, MARIE NAKLADALOVÁ ${ }^{2}$, MARKETA KALETOVA ${ }^{1}$, MARKETA SOVOVA ${ }^{3}$, \\ LENKA RADOVA ${ }^{4}$, and MICHAELA KRIBSKA ${ }^{2}$
}

${ }^{1}$ Palacký University, Olomouc, Czech Republic

Department of Internal Medicine I - Cardiology, University Hospital Olomouc and Faculty of Medicine and Dentistry

${ }^{2}$ Palacký University, Olomouc, Czech Republic

Department of Occupational Medicine, University Hospital Olomouc and Faculty of Medicine and Dentistry

${ }^{3}$ Palacký University, Olomouc, Czech Republic

Faculty of Medicine and Dentistry

${ }^{4}$ Palacký University, Olomouc, Czech Republic

Institute of Molecular and Translational Medicine, Faculty of Medicine and Dentistry

\begin{abstract}
Objectives: Health care workers constitute a high-risk occupational category owing to the character of their work that includes high-risk environment, shift work and mental as well as physical stress. In occupational medicine, caring for their health condition should be a priority and include measures aimed at preventing cardiovascular diseases. The study aimed at determining the prevalence of cardiovascular disease (CVD) risk factors in employees of a large hospital and assessing their effect on the incidence of cardiovascular events. Materials and Methods: The group comprised 3124 employees with a mean age of 36.1 years $(\mathrm{SD}=11.4)$, out of whom 562 were males (mean age of 37.1 years, range: $18-72 ; \mathrm{SD}=12.26$ ) and 2562 were females (mean age of 35.9 years, range: $18-68 ; \mathrm{SD}=11.24$ ). At their initial examination, the employees filled in a questionnaire on basic CVD risk factors (according to valid recommendations). This was supplemented with objective data to determine the risk of CVD using valid charts. From this group, a subset of persons at a high or intermediate risk was selected, comprising 247 individuals with a mean age of 54.1 years $(S D=5.73)$. After $5-9$ years (mean $7.24 \pm 1.38$ years), they either underwent another examination or their health status was ascertained by phone or in a computer database. The end point was the incidence of cardiovascular events (sudden death, acute myocardial infarction, unstable angina pectoris, percutaneous coronary intervention, cardiac failure, stroke or transient ischemic attack). Results: The end point was noted in a total of 15 males $(6.07 \%)$ and 6 females (2.42\%), being statistically significantly present in managers (males $\mathrm{p}<0.00007$, females $\mathrm{p}<0.00001)$, male physicians/surgeons $(\mathrm{p}<0.025)$, tertiary-educated males $(\mathrm{p}<0.0095)$, female smokers $(p<0.015)$, male ex-smokers $(p<0.007)$, overweight or obese males $(p<0.02)$ and those with the waist-to-hip ratio above $1.0(\mathrm{p}<0.005)$. Conclusions: Cardiovascular events are most likely to occur in obese male physicians/surgeons holding managerial positions and in female managers.
\end{abstract}

Key words:

Cardiovascular, Event, Hospital employees, Risk factors

Received: November 14, 2013. Accepted: December 16, 2013.

The infrastructural part of the project (Institute of Molecular and Translational Medicine) was supported by the Operational Programme Research and Development for Innovations (project CZ.1.05/2.1.00/01.0030).

Corresponding author: E. Sovova, Department of Internal Medicine I - Cardiology, University Hospital Olomouc, I.P. Pavlova 5, 77520 Olomouc, Czech Republic (e-mail: eliska.sovova@fnol.cz). 


\section{INTRODUCTION}

Health care workers constitute a high-risk occupational category owing to the character of their work that includes high-risk environment, shift work and mental as well as physical stress. Caring for their health condition should be a priority and include measures aimed at preventing cardiovascular diseases. As early as in the 2 nd century A.D., Galen claimed that "the physician will hardly be thought very careful of the health of his patient if he neglects his own" [1].

Occupational medicine of the future has to consider the dominant diseases in the population, primarily cardiovascular disease (CVD), to a greater extent than now, even if these are not listed as occupational diseases [2].

In recent years, studies have been published that illustrate relationships between psychosocial work environment and health [3]. The effect of work characteristics on the development of ischemic heart disease may account for as much as $20 \%$ increase in the prevalence of the condition [4]. In a study of 1053 patients with acute myocardial infarction, Bortkiewicz et al. [5] found that the most frequent occupational risk factors were work-related stress, experienced by $54.2 \%$ of the examined subjects, occupational noise (45.5\%), dust (41.7\%) and various chemical factors $(33 \%)$.

The study aimed at determining the prevalence of cardiovascular risk factors in employees of a large hospital and assessing their effect on the incidence of cardiovascular events.

\section{MATERIALS AND METHODS}

The group comprised 3124 employees with a mean age of 36.1 years $(S D=11.4)$, out of whom 562 were males with a mean age of 37.1 years (range: $18-72 ; \mathrm{SD}=12.26$ ) and 2562 were females with a mean age of 35.9 years (range: $18-68 ; \mathrm{SD}=11.24$ ). At their initial examination in 2002-2004, the employees filled in a questionnaire on basic CVD risk factors. This was supplemented with objective data (blood pressure [BP], weight, height, body mass index [BMI] and lipid metabolism) to determine the risk of CVD using the then valid charts [6]. Risk factors were defined according to valid recommendations. A physician evaluated the protocols and suggested targeted risk intervention. This was done in the form of a personalized letter; if the current risk factors required further followup or treatment, such recommendations were included in the letter.

For further analysis, a subgroup of persons at a high or intermediate risk (10\% or more using the Framingham Risk Score) was selected, comprising 247 individuals (115 males) with a mean age of 54.1 years (SD $=5.73)$, and labeled as At Risk. In these persons, the risk was recalculated using the new PROCAM scoring system [7]. After 5-9 years (mean $7.24 \pm 1.38$ years), they either underwent another examination or their health status was ascertained by phone or in a computer database. The end point was the incidence of a cardiovascular event (sudden death, acute myocardial infarction, unstable angina pectoris, percutaneous coronary intervention for ischemic heart disease, cardiac failure, stroke or transient ischemic attack). The subgroup was divided into 5 categories, according to their professions, as follows: physicians/surgeons (Category 1: 58 persons, $23.48 \%$ ), nurses (Category 2: 42 persons, 17\%), auxiliary personnel (Category 3: 84 persons, 34\%), other tertiary-educated workers (Category 4: 30 persons, 12.14\%) and secretaries (Category $5: 33$ persons, $13.36 \%$ ).

It was also noted whether the subjects held a managerial position (head or charge nurses, departmental head). This was the case for 29 males (11.74\%) and 9 females (3.28\%). According to the criteria published by the International Society of Hypertension, hypertension was defined as repeatedly elevated systolic BP $\geq 140 \mathrm{~mm} \mathrm{Hg}$ or diastolic $\mathrm{BP} \geq 90 \mathrm{~mm} \mathrm{Hg}$ on two out of three readings during at least 2 visits to a physician (casual BP) or the use of 
antihypertensives and a known diagnosis of hypertension. The measurements were made with a classic mercury sphygmomanometer. The final BP value was calculated as the mean from repeated measurements.

Adequate physical activity was, in accordance with the valid guidelines, defined as activity lasting for either a minimum of 20 min daily or one hour twice a week. Low activity was defined as less than adequate. No activity meant only doing household chores or walking to and from work. Lipid metabolism disorder was defined as plasma cholesterol level $\geq 5 \mathrm{mmol} / \mathrm{l}$ or administration of hypolipidemic therapy. According to the WHO, smokers were persons smoking regularly at least one cigarette daily.

Obesity was defined as BMI $\geq 30$; overweight persons were those with $\mathrm{BMI} \geq 25$ and $<30$.

Concentrations of total cholesterol, high-density lipoprotein (HDL) cholesterol, low-density lipoprotein (LDL) cholesterol and triglycerides were analyzed in fresh serum from morning venous blood samples taken after a 12-hour fasting period according to the manufacturer's instructions.

\section{Ethics}

The study was approved by the Ethics Committee of the Faculty of Medicine and Dentistry, Palacký University Olomouc.

\section{Statistics}

Statistical analyses were carried out at a significance level of 0.05 using the Statistica 10 software (StatSoft, Inc). Statistical comparisons were made with the unpaired t-test; for categorical variables, Pearson's Chi test was used.

\section{RESULTS}

The prevalence rates of risk factors in the At Risk group are shown in Tables 1 and 2. The group comprises high percentages of smokers $(51.4 \%)$, persons with a family history (43.7\%), those with low or no physical activity (39.6\%), overweight or obese subjects $(68.4 \%)$ and individuals with high cholesterol levels (80.97\%).

The end point was noted in a total of 15 males $(6.07 \%)$ and 6 females $(2.42 \%)$.

Table 1. Prevalence of cardiovascular risk factors in employees with a risk of more than $10 \%$ (Framingham)

\begin{tabular}{lrrrrrr}
\hline & \multicolumn{2}{c}{$\begin{array}{c}\text { Total } \\
\text { Variable }\end{array}$} & \multicolumn{2}{c}{$\begin{array}{c}\text { Males } \\
(\mathrm{N}=247)\end{array}$} & \multicolumn{2}{c}{$\begin{array}{c}\text { Females } \\
(\mathrm{N}=115)\end{array}$} \\
\cline { 2 - 7 } & \multicolumn{1}{c}{$\mathrm{n}$} & \multicolumn{1}{c}{$\%$} & $\mathrm{n}$ & \multicolumn{1}{c}{$\%$} & $\mathrm{n}$ & \multicolumn{1}{c}{$\%$} \\
\hline Smoker & 127 & 51.41 & 43 & 37.39 & 84 & 63.63 \\
Ex-smoker & 7 & 2.83 & 6 & 5.21 & 1 & 0.75 \\
Hypertension & 70 & 28.34 & 35 & 30.43 & 35 & 26.51 \\
Diabetes mellitus & 15 & 6.07 & 4 & 3.47 & 11 & 8.33 \\
Positive family history & 108 & 43.72 & 46 & 40.00 & 62 & 46.96 \\
Overweight & 125 & 50.60 & 70 & 60.86 & 55 & 41.66 \\
Obesity & 44 & 17.81 & 18 & 15.65 & 26 & 19.69 \\
Severe obesity & 4 & 1.61 & 2 & 1.73 & 2 & 1.51 \\
Lipid metabolism disorder & 200 & 80.97 & 85 & 73.91 & 115 & 87.12 \\
Adequate physical activity & 136 & 55.06 & 67 & 58.26 & 69 & 52.27 \\
Low physical activity & 73 & 29.55 & 31 & 26.95 & 42 & 31.81 \\
No physical activity & 25 & 10.12 & 13 & 11.30 & 12 & 9.09 \\
\hline
\end{tabular}


Table 2. Values of selected parameters in employees with a risk of more than $10 \%$ (Framingham)

\begin{tabular}{|c|c|c|c|c|c|c|}
\hline \multirow{2}{*}{ Variable } & \multicolumn{3}{|c|}{$\begin{array}{c}\text { Males } \\
(\mathrm{N}=115)\end{array}$} & \multicolumn{3}{|c|}{$\begin{array}{l}\text { Females } \\
(\mathrm{N}=132)\end{array}$} \\
\hline & $\mathrm{M}$ & $\mathrm{Me}$ & SD & $\mathrm{M}$ & $\mathrm{Me}$ & $\mathrm{SD}$ \\
\hline BMI & 27.18 & 26.60 & 4.450 & 26.92 & 26.80 & 4.16 \\
\hline WHR & 0.75 & 0.92 & 0.370 & 0.78 & 0.82 & 0.18 \\
\hline Cholesterol (mmol/l) & 5.90 & 5.91 & 1.060 & 6.46 & 6.48 & 1.17 \\
\hline LDL cholesterol (mmol/l) & 3.52 & 3.51 & 1.190 & 3.96 & 3.93 & 1.17 \\
\hline HDL cholesterol $(\mathrm{mmol} / \mathrm{l})$ & 1.33 & 1.28 & 0.355 & 1.59 & 1.52 & 0.47 \\
\hline Triglycerides (mmol/l) & 2.40 & 1.67 & 3.440 & 1.81 & 1.54 & 1.04 \\
\hline
\end{tabular}

BMI - body mass index; WHR - waist-to-hip ratio; LDL - low-density lipoprotein; HDL - high-density lipoprotein.

$\mathrm{M}$ - mean; Me - median; SD - standard deviation.

Table 3. Values of selected parameters in employees with a risk of more than $10 \%$ (Framingham) and the correlation with the presence of the CVD end point

\begin{tabular}{|c|c|c|c|c|c|c|c|c|c|}
\hline \multirow[b]{2}{*}{ Variable } & \multicolumn{3}{|c|}{ Total } & \multicolumn{3}{|c|}{ Males } & \multicolumn{3}{|c|}{ Females } \\
\hline & $\begin{array}{l}\text { CV event- } \\
\text { free } \\
(\mathrm{N}=208)\end{array}$ & $\begin{array}{l}\text { CV event- } \\
\text { positive } \\
(\mathrm{N}=21)\end{array}$ & $\mathrm{p}$ & $\begin{array}{l}\text { CV event- } \\
\text { free } \\
(\mathrm{N}=91)\end{array}$ & $\begin{array}{l}\text { CV event- } \\
\text { positive } \\
(\mathrm{N}=15)\end{array}$ & $\mathrm{p}$ & $\begin{array}{l}\text { CV event- } \\
\text { free } \\
(\mathrm{N}=117)\end{array}$ & $\begin{array}{l}\text { CV event- } \\
\text { positive } \\
(\mathrm{N}=6)\end{array}$ & $\mathrm{p}$ \\
\hline$\overline{\text { Age }}$ & 53.78 & 55.82 & 0.042 & 53.49 & 54.66 & 0.56 & 54.01 & 54.16 & 0.93 \\
\hline BMI & 27.09 & 26.77 & 0.660 & 27.28 & 28.91 & 0.12 & 26.95 & 26.01 & 0.60 \\
\hline WHR & 0.76 & 0.81 & 0.330 & 0.74 & 0.88 & 0.18 & 0.77 & 0.92 & 0.06 \\
\hline $\begin{array}{l}\text { Cholesterol total } \\
(\mathrm{mmol} / \mathrm{l})\end{array}$ & 6.30 & 5.93 & 0.060 & 6.04 & 5.85 & 0.52 & 6.51 & 6.45 & 0.89 \\
\hline $\begin{array}{l}\text { LDL cholesterol } \\
\quad(\mathrm{mmol} / \mathrm{l})\end{array}$ & 3.78 & 3.63 & 0.480 & 3.49 & 3.63 & 0.69 & 4.00 & 4.03 & 0.94 \\
\hline $\begin{array}{l}\text { HDL cholesterol } \\
(\mathrm{mmol} / \mathrm{l})\end{array}$ & 1.46 & 1.46 & 0.980 & 1.31 & 1.34 & 0.72 & 1.59 & 1.59 & 0.99 \\
\hline Triglycerides $(\mathrm{mmol} / \mathrm{l})$ & 2.17 & 1.81 & 0.400 & 2.66 & 1.91 & 0.45 & 1.79 & 1.80 & 0.99 \\
\hline
\end{tabular}

$\mathrm{CV}$ - cardiovascular.

Other abbreviations as in Table 2.

As for the continuous variables (Table 3 ) analyzed in the entire group, there was a statistically significant correlation noted between the waist-to-hip ratio (WHR) and the presence of the CVD end point ( $p=0.04)$, see Figure 1.

The CVD end point was statistically significantly present in managers (males: $p<0.00007$, females: $p<0.00001$ ), male physicians/surgeons $(\mathrm{p}<0.025)$, tertiary-educated males $(\mathrm{p}<0.0095)$, female smokers $(\mathrm{p}<0.015)$, male ex-smokers $(\mathrm{p}<0.007)$, overweight or obese males $(\mathrm{p}<0.02)$ and those with the WHR above $1.0(\mathrm{p}<0.005)$.

\section{DISCUSSION}

The prevalence rates of risk factors in the group are high, in particular the numbers of smokers, individuals with hypertension, low or no physical activity, overweight or 


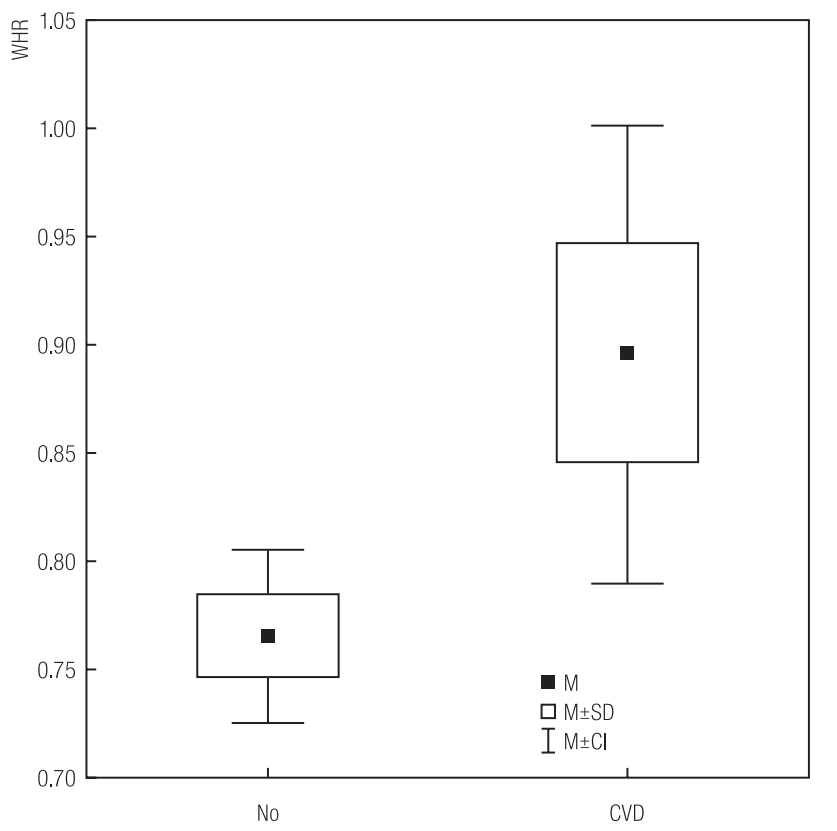

$\mathrm{M}$ - mean; SD - standard deviation; CI - confidence interval. $\mathrm{p}>0.05$.

Fig. 1. Correlation between the waist-to-hip ratio (WHR) and the presence of the cardiovascular disease (CVD) end point

obese persons and those with lipid metabolism disorder. In a survey concerning risk factors in nearly 2500 physicians, Ramachandran [8] found statistically significantly higher rates of risk factors as compared with a matched sample of the general population. A study of 191 physicians by Belkić and Nedić [9] reported low cardiovascular risk in only $12 \%$ of the subjects.

The presence of a severe cardiovascular end point was statistically significantly associated mainly with managerial positions held by both males and females. Nedić et al. [10] demonstrated that physicians with a history of severe CVD (acute myocardial infarction, angina pectoris, arrhythmias) had higher Occupational Stress Index scores, especially in the following dimensions: high demands and threat avoidance. Böckelmann et al. [11] studied 163 university employees with leadership tasks. A thorough physical examination, blood tests and a 24-hour ECG were done at baseline. Groups with distinct work-related behaviors differed in relevant factors of work, lifestyle, and methods of coping with stress such as "negative" strategies, "resignation" and "avoidance tendency". To the best of our knowledge, no study has been published on the effect of health care managerial positions on the incidence of cardiovascular events. Physicians are more at risk for occupational stress than the general population, as seen from a Japanese study, with a work stress score being 114 in 383 anesthesiologists as compared with 100 in average workers [12], or a study in Taiwan [13]. Moreover, the Taiwanese study reported a higher proportion of persons suffering from depression among physicians than in the general population $(13.3 \%$ vs. 3.7\%). In a study investigating on-call workload among Finnish anesthetists, a total of $68 \%$ felt stressed [14]. Certain specialists such as surgeons are more stressed than others [9,15]. In our study, the effect of specialization was not analyzed. Schmid et al. [16] compared various occupational groups and found that hospital employees were often frustrated and felt that their work was not appreciated, as compared with other workers in other industries. Literature data suggest that females are more at risk for occupational stress [17,18].

Unlike in a study by Holtermann et al. [19] reporting an association between a higher risk of ischemic heart disease and low social class, physicians/surgeons were more at risk than other categories in our study. This may be explained mainly by the group composition, with higher proportions of tertiary- or secondary-educated individuals as commonly seen in health care facilities.

As seen from the statistical analysis, smoking increased the risk of $\mathrm{CV}$ events only in females and in male ex-smokers; however, this is explained by the fact that all females with a history of cardiovascular events were smokers. On the other hand, it may be assumed that males stopped smoking due to certain problems. There were 43 male (37.39\%) and 47 female (35.6\%) smokers in the group. Our data are consistent with a study by Belkić and Nedić [20] showing a prevalence of smoking among female physicians of $31.3 \%$, but in contradiction with a Stanford University 
study [21] with only $5 \%$ of smokers among preventive cardiovascular nurses.

Another factor affecting the CVD end point was overweight, obesity and the WHR above 1.0 in males. In this study, the risk factor was highly prevalent, similar to a study by Grace and Semple [22].

To a certain extent, cardiovascular events are also influenced by shift work [23]. Jermendy et al. [24] reported a higher prevalence of certain CVD risk factors (hypertension, weight, BMI, etc.) in shift workers. The effect was not investigated in this study; however, it is our intention to include it in future research.

Health care managers are at a very high risk of developing severe cardiovascular events. Preventing the risk factors including stress should be an integral part of care for these individuals.

\section{REFERENCES}

1. Ghosh AK, Joshi SR. Physician's health: time to take care. JAPI. 2008;56:13-4.

2. Pfister EA, Böckelmann I, Peter B, Wollenberg H. [Possibilities of occupational medicine in the repression of work-related cardiovascular diseases]. Zentralblatt Arbeitsmedizin Arbeitsschutz Ergon. 2006;56:144-55. German.

3. Soderberg M, Rosengren A, Hillstrom J, Lissner L, Toren K. A cross sectional study of the relationship between job demand-control, effort-reward imbalance and cardiovascular heart disease risk factors. BMC Public Health. 2012;12: 1102-4, http://dx.doi.org/10.1186/1471-2458-12-1102.

4. Nurminen M, Karjalainen A. Epidemiologic estimate of the proportion of fatalities related to occupational factors in Finland. Scand J Work Environ Health. 2001;27:295, http:// dx.doi.org/10.5271/sjweh.605.

5. Bortkiewicz A, Gadzicka E, Siedlecka J, Szyjkowska A, Viebig P, Wranicz JK, et al. Work-related risk factors of myocardial infarction. Int J Occup Med Environ Health. 2010;23(3):255-65, http://dx.doi.org/10.2478/v10001-010-0030-7.
6. Wood D, de Backer D, Faergeman O, Graham I, Mancia G, Pyorala K. Prevention of coronary heart disease in clinical practice. Recommendations of the Second Joint Task Force of European and other Societies on coronary prevention. Eur Heart J. 1998;19:1434-503, http://dx.doi.org/10.1053/ euhj.1998.1243.

7. Assmann G, Cullen P, Schulte H. Simple scoring scheme for calculating the risk of acute coronary events based on the 10-year follow-up of the Prospective Cardiovascular Münster (PROCAM) study. Circulation. 2002;105:310-5, http://dx.doi.org/10.1161/hc0302.102575.

8. Ramachandran A, Snehalatha C, Yamuna A, Murugesan N. High prevalence of cardiometabolic risk factors among young physicians in India. JAPI. 2008;56:17-20.

9. Belkić K, Nedić O. Night work, total occupational burden and cancer/cardiovascular risk factors in physicians. J Med Pregl. 2012;65:461-9, http://dx.doi.org/10.2298/ MPNS1212461B.

10. Nedić O, Belkić K, Filipović D, Jocić N. Work stressors among physicians with and without the acquired cardiovascular disorders: assessment using the Occupational Stress Index. Med Pregl. 2008;61:226-34, http://dx.doi.org/10.2298/ MPNS0806226N.

11. Böckelmann I, Pfister E, Thielmann B. [Detection of cardiovascular risk in university employees with leadership tasks]. Prev Gesundheitsforderung. 2010;5:223-30, http://dx.doi. org/10.1007/s11553-010-0229-2. German.

12. Kawasaki K, Sekimoto M, Ishaki T, Imanaka Y. Work stress and workload of full time anesthesiologists in acute care hospitals in Japan. J Anesth. 2009;23:235-41, http://dx.doi. org/10.1007/s00540-008-0736-x.

13. Wang LJ, Chen CK, Hsu SC, Lee SY, Wang CS, Yeh WY. Active job, healthy job? Occupational stress and depression among physicians in Taiwan. Ind Health. 2011;49:173-84, http://dx.doi.org/10.2486/indhealth.MS1209.

14. Lindfors PM, Nurmi KE, Meretoja OA, Luukkonen RA, Viljanen AM, Leino TJ, et al. On call stress among Finnish anaesthetists. Anaesthesia. 2006;61.856-66. 
15. Bohrer T, Koller M, Schlitt HJ, Bauer H. Workload and quality of life of surgeons. Results and implications of a largescale survey by the German Society of Surgery. Langenbecks Arch Surg. 2011;396:669-76, http://dx.doi.org/10.1007/ s00423-011-0791-x.

16. Schmid K, Drexler H, Fischmann W, Uter W, Kiesel J. [Which occupational groups in a hospital are particularly stressed?]. Dtsch Med Wochenschr. 2011;136:1517-22, http://dx.doi. org/10.1055/s-0031-1281547.

17. Kinzl JF, Traweger C, TrefaltE, Riccabona U, Lederer W. Work stress and gender dependent coping strategies in anesthesiologists at a university hospital. J Clin Anesth. 2007;19:334-8, http://dx.doi.org/10.1016/j.jclinane.2006.08.014.

18. Nedić O, Belkić K, Filipović D, Jocić N. Gender as a key effect modifier of the relationship between physician work stressors and the acquired cardiovascular disorders.

J Med Pregl. 2008;61:343-9, http://dx.doi.org/10.2298/ MPNS0808343N.

19. Holtermann A, Mortensen OS, Sogaard K, Gyntelberg F, Suadicani P. Risk factors for ischemic heart disease mortality among men with different occupational physical demands. A 30-year prospective cohort study. BMJ. 2012;2:1-9.
20. Belkić K, Nedić O. Workplace stressors and lifestyle-related cancer risk factors among female physicians: assessment using the Occupational Stress Index. J Occup Health. 2007;49: 61-71, http://dx.doi.org/10.1539/joh.49.61.

21. Fair JM, Gulanick M, Braun LT. Cardiovascular risk factors and lifestyle habits among preventive cardiovascular nurses. J Cardiovasc Nurs. 2009;24:277-86, http://dx.doi. org/10.1097/JCN.0b013e3181a24375.

22. Grace J, Semple S. The prevalence of cardiovascular disease risk factors in normotensive, pre-hypertensive and hypertensive South African colliery executives. Int J Occup Med Environ Health. 2012;25(4):375-82, http://dx.doi.org/10.2478/ s13382-012-0045-3.

23. Esquirol Y, Perret B, Ruidavets JB, Marquie JC, Dienne E, Niezborala M, et al. Shift work and cardiovascular risk factors: new knowledge from the past decade. Arch Cardiovasc Dis. 2011;104:636-68, http://dx.doi.org/10.1016/ j.acvd.2011.09.004.

24. Jermendy G, Nadas J, Hegyi I, Vasas I, Hidvegi T. Assessment of cardiometabolic risk among shift workers in Hungary. Health Quality Life Outcomes. 2012;10:18-24, http:// dx.doi.org/10.1186/1477-7525-10-18.

This work is available in Open Access model and licensed under a Creative Commons Attribution-NonCommercial 3.0 Poland License - http://creativecommons.org/ licenses/by-nc/3.0/pl/deed.en. 